\title{
Educação inclusiva: os avanços legislativos nos 30 anos da Constituição Federal de 1988
}

\author{
Flávia Piva Almeida Leite* \\ Adriano Fernando Segantin**
}

\section{Resumo}

O objetivo deste estudo é analisar os avanços legislativos ocorridos após a vigência da Constituição Federal de 1988, notadamente no tocante à realização do direito fundamental à educação da pessoa com deficiência no Direito brasileiro. Para tanto, foram abordados os aspectos históricos e sociais da exclusão e inclusão dessa parcela da população, a disciplina do direito fundamental à educação inclusiva das pessoas com deficiência na Constituição Federal, nas leis infraconstitucionais e no Estatuto da Pessoa com deficiência. Para o desenvolvimento deste artigo, foi adotado o método teórico-jurídico, com raciocínio dedutivo e técnica de pesquisa bibliográfica e documental.

Palavras-chave: Educação. Educação inclusiva. Pessoa com deficiência. Evolução legislativa.

\section{Inclusive education: the legislative advances in the 30 years of the Federal Constitution of 1988}

\section{Abstract}

The purpose of this study is to analyze the legislative advances that occurred after the validity of the Federal Constitution of 1988, especially regarding

* Doutora em Direito Urbanístico pela Pontifícia Universidade Católica (PUCSP). Mestre em Direito Constitucional pela Instituição Toledo de Ensino (ITE - Bauru/SP). Pós-graduada em Gerente de Cidades pela Fundação Armando Álvares Penteado (FAAP - São Paulo/SP). Professora Permanente do Programa de mestrado em Direito da Universidade Estadual Paulista "Julio de Mesquita Filho" - UNESP-Franca e Professora Assistente Doutora do Departamento de Ciências Humanas - FAAC - UNESP-Bauru.

E-mail: flavia.leite@unesp.br

** Pós-graduado em Direito Tributário pelo Centro de Extensão Universitária - CEU. Graduado em Direito pelas Faculdades Integradas de Jaú/SP. Graduado em Administração de Empresas pela Faculdade de Administração de Empresas de Jahu. Advogado. E-mail: adrianosegantin@uol.com.br 
the realization of the fundamental right to the education of people with disabilities in Brazilian Law. The historical and social aspects of the exclusion and inclusion of this part of the population, the discipline of the fundamental right to the inclusive education of persons with disabilities in the Federal Constitution, the infraconstitutional laws and the Statute of the Person with Disabilities were addressed. For the development of this article, was adopted the theoretical-legal method with deductive reasoning and bibliographic and documentary research technique.

Keywords: Education. Inclusive education. Disabled person. Legislative developments.

\section{Educación inclusiva: los avances legislativos en los 30 años de la Constitución Federal de 1988}

\section{Resumen}

El propósito de este estudio es analizar la evolución de la edad que se produjo después de la validación de la Constitución Federal de 1988, especialmente en lo que se refiere a la realización de la base fundamental de la educación de las personas con discapacidad en la Ley del Estado. y la inclusión de esta parte de la población, la disciplina del derecho fundamental a la educación de las personas con discapacidad en la Constitución Federal, los derechos constitucionales y el Estatuto de las personas con discapacidad. Para el desarrollo de este artículo, se adoptó el método legal con deductiva de razonamiento y bibliografía y documentación de investigación técnica.

Palabras clave: educación. Educación inclusiva. Persona discapacitada. Desarrollos legislativos.

\section{Introdução}

Somente após a ocorrência das duas grandes Guerras Mundiais a sociedade em geral começa a esboçar uma sensibilização e uma conscientização positiva, especialmente voltadas para as pessoas com deficiência.

A partir de 1980, a Assembleia Geral da ONU passa a aprovar resoluções com o intuito de derrubar a prática da exclusão social a que foram submetidas, por vários séculos, as pessoas com deficiência, começando a inseri-las nos sistemas sociais como o trabalho, a família, o lazer e a educação. 
No ano de 1993, a Assembleia Geral da ONU adotou o documento sobre a Equiparação de Oportunidades para as Pessoas com Deficiência (Resolução 44/70) que, em todas as suas definições, trazia de forma implícita o princípio da igualdade de direitos, dandose início ao movimento de inclusão social que, inspirado pelos princípios da celebração de diferenças, do direito de pertencer, da valorização da diversidade humana, da solidariedade humanitária, da igual importância das minorias e cidadania com qualidade de vida, demandará a construção de um novo tipo de sociedade: uma sociedade mais democrática, mais tolerante e mais inclusiva.

O Brasil não destoou dessa evolução, que já se vinha operando no mundo todo. Todavia, foi somente com a Constituição Federal de 1988 que o tratamento da pessoa com deficiência se modifica, passando a um enfoque muito mais preocupado com a inclusão social. Elevou, em seu artigo $1^{\circ}$., III, o valor da dignidade da pessoa humana a princípio fundamental desse novo Estado. Consagrou como objetivos fundamentais construir uma sociedade livre, justa e solidária, erradicar a pobreza e a marginalização e reduzir as desigualdades sociais e promover o bem de todos, sem preconceitos de origem, raça, sexo, cor, idade e quaisquer formas de discriminação (artigo $3^{\circ}$. e incisos). Determinou a prevalência dos direitos humanos entre os princípios a reger suas relações internacionais com os demais países (artigo 4, II). E, por meio do caput e $\int 1^{\circ}$. do seu artigo $5^{\circ}$, assegurou o princípio da igualdade, que passa a ser considerado, dentro desse novo enfoque introduzido pela Lei Maior, como o valor mais alto dos direitos fundamentais, funcionando como regra mestra de toda a hermenêutica constitucional e infraconstitucional.

No tocante ao direito fundamental à educação, o referido texto constitucional deu tratamento minucioso, com a indicação de princípios que devem nortear sua realização, a destinação obrigatória de recursos, e a previsão de situações importantes, relacionadas às minorias, entre as quais se destacam as pessoas com deficiência.

O Brasil, na busca pela implementação dos direitos das pessoas com deficiência, assina no dia 30 de março de 2007 a 
Convenção sobre os Direitos das Pessoas com Deficiência e seu Protocolo Facultativo, promulgados pela Organização das Nações Unidas. ${ }^{1}$ Sua eficácia foi reconhecida em âmbito nacional com a edição do Decreto-legislativo 186/08. ${ }^{2}$

A regulamentação específica da educação, para esse segmento da sociedade, foi objeto da Lei 13.146/2015, o Estatuto da Pessoa com Deficiência, marco legal essencial para a concretização de seus direitos fundamentais.

Este trabalho identifica e sistematiza o processo de evolução da inclusão das pessoas com deficiência, especialmente no que refere ao aspecto da evolução legislativa implementada após o advento da Constituição Federal de 1988, no que tange ao direito à educação. Para o seu desenvolvimento, foi adotado o método teórico-jurídico com raciocínio dedutivo e técnica de pesquisa bibliográfica e documental.

Para saber sobre o processo da elaboração da Convenção, ler texto de LOPES, Laís Vanessa Carvalho de Figueiredo. Convenção sobre os direitos das pessoas com deficiência da ONU. In: GUGEL, Maria Aparecida; COSTA FILHO, Waldir Macieira da; RIBEIRO, Lauro Luiz Gomes (Org.). Deficiência no Brasil - uma abordagem integral dos direitos das pessoas com deficiência. Florianópolis: Obra Jurídica, 2007, p. 49 a 53.

2 DECRETO LEGISLATIVO Nº. 186, DE 9 DE JULHO DE 2008 - DOU 10.07.2008 - Aprova o texto da Convenção sobre os Direitos das Pessoas com Deficiência e de seu Protocolo Facultativo, assinados em Nova Iorque, em 30 de março de 2007.

O Congresso Nacional decreta:

Artigo $1^{\circ}$. Fica aprovado, nos termos do $\int 3^{\circ}$. do artigo $5^{\circ}$. da Constituição Federal, o texto da Convenção sobre os Direitos das Pessoas com Deficiência e de seu Protocolo Facultativo, assinados em Nova Iorque, em 30 de março de 2007.

Parágrafo único. Ficam sujeitos à aprovação do Congresso Nacional quaisquer atos que alterem a referida Convenção e seu Protocolo Facultativo, bem como, quaisquer outros ajustes complementares que, nos termos do inciso I do caput do artigo 49 da Constituição Federal, acarretem encargos ou compromissos gravosos ao patrimônio nacional.

Artigo $2^{\circ}$. Este Decreto Legislativo entra em vigor na data de sua publicação. Senado Federal, em 9 de julho de 2008. (Senador GARIBALDI ALVES FILHO - Presidente do Senado.) 


\section{Da exclusão à inclusão da pessoa com deficiência}

As dificuldades passadas pelas pessoas com deficiência pelos muitos séculos da história do homem jamais deixaram de existir. Essa verdade sempre foi válida em todos os quadrantes da Terra, em qualquer época, sendo válida também para todos os períodos da história do Brasil. Na verdade, a pessoa com deficiência no Brasil foi considerada por vários séculos dentro da categoria mais ampla dos miseráveis, talvez o mais pobre dos pobres. Quando essas pessoas nasciam de famílias mais abastadas, certamente, passavam o restante de seus dias escondidas em suas grandes mansões, fazendas ou em casas de campo de suas famílias, ficando totalmente excluídas do convívio social, permanecendo como um peso para as suas respectivas famílias (SILVA, 2009).

A partir do século XX, a sociedade em geral passa a esboçar uma sensibilização e uma conscientização positiva em relação às pessoas com deficiência. Pode-se dizer que essa alteração se deu por vários fatores: uma filosofia social mais voltada para a valorização do homem, do engajamento de muitos setores da sociedade movidos pelo bem-estar comum, em consequência dos evidentes progressos das ciências e suas aplicações práticas, em todos os campos, mas, especialmente, pelas ações destruidoras ocasionadas pelas Grandes Guerras Mundiais. $^{3}$

Ao final da Segunda Guerra Mundial, o problema dos soldados vítimas de deficiências causadas pela guerra atrai a atenção, não só da sociedade, mas também da Organização das Nações Unidas (ONU) que, com outras organizações de caráter internacional ${ }^{4}$ (Fundo de Emergência das Nações Unidades para

$3 \quad$ Nesse mesmo sentido, esclarece Luiz, que "um importante divisor de águas para o estudo da proteção das pessoas portadoras de deficiência foi a ocorrência das duas grandes guerras mundiais, que fez aumentar, desgraçadamente, o número de pessoas portadoras de deficiência de locomoção e de audição" (ARAUJO, 1997, p. 15).

4 Segundo anota Otto Marques da Silva, em sua obra Epopeia Ignorada, as responsabilidades das Organizações Internacionais foram sendo gradativamente definidas, estando envolvidas no desenvolvimento de programas de assistên- 
as Crianças - UNICEF, a Organização Internacional do Trabalho - OIT, a Organização Mundial de Saúde-OMS, a Organização das Nações Unidas para Refugiados e a Organização das Nações Unidas para Educação, Ciência e Cultura - UNESCO), criam grandes programas assistenciais com ênfase especial para dar soluções aos inúmeros e sérios problemas sociais causados pelos elevados contingentes de população vítimas das atividades da guerra. O problema da deficiência ocasionado pelos males da guerra era tão significativo que demandou a concentração de esforços em programas de reabilitação dessas pessoas.

Começa a haver uma conscientização no sentido de compreender que as pessoas com deficiência necessitavam não só dos cuidados que as instituições especiais pudessem lhes prover, mas, também, de atenção pessoal, carinho, relacionamento familiar, enfim, de um ambiente que possibilitasse alguma participação na vida comunitária, como qualquer pessoa.

cia técnica ou de financiamento de projetos localizados nos países em desenvolvimento. Esses projetos cobriam os mais variados aspectos da educação e da reabilitação de pessoas com deficiência, por meio de especialistas em campo, bolsas de estudos para profissionais e publicações consideradas relevantes. A Unidade de Reabilitação de Pessoas com Deficiência na ONU, com sede em Nova Iorque, ficou encarregada de variados aspectos de Planejamento, Administração, Legislação, Aspectos Sociais, Aspectos Psicológicos e Próteses. A Organização Internacional do Trabalho, sediada em Genebra, cobria todos os aspectos de vida de trabalho das pessoas com deficiência. A Organização das Nações Unidas para Refugiados e a Organização das Nações Unidas para Educação, Ciência e Cultura - UNESCO, com sede em Paris, tem como competência técnica o desenvolvimento de atividades de assistência técnica em educação especial para pessoas com deficiência. A OMS, com sede em Genebra, tem a responsabilidade de promover a saúde, em sentido amplo, às pessoas com deficiência. E o Fundo de Emergência das Nações Unidades para as Crianças - UNICEF, sediado em Nova Iorque, nas instalações da ONU, somente prestava assistência de natureza financeira a projetos que tinham a aprovação técnica da relevante Agência das Nações Unidas, ou seja, da Organização Mundial de Saúde, da UNESCO, da Organização das Nações Unidas para Refugiados e da própria Unidade de Reabilitação de Pessoas Deficientes do Bureau de Assuntos Sociais da ONU. (Cf. Epopeia ignorada. Século XX. Responsabilidades das Organizações Internacionais. Parte I. Capítulo Décimo segundo. CD Epopeia Ignorada, Cotia: Editora Faster, 2009.) 
Com esse tipo de raciocínio dominante, a Assembleia Geral da ONU realizou muitos esforços para dar cobertura aos problemas sociais que as pessoas com deficiências enfrentavam, tanto que a partir dos anos 50, com o Conselho Econômico e Social das Nações Unidas, passou a aprovar resoluções sobre prevenção e reabilitação.

No ano de 1955, a OIT lança a recomendação nº 99 sobre a Reabilitação de Pessoas Portadoras de Deficiência. No ano de 1971, a Assembleia Geral da ONU aprova a resolução no . 28/56, Declaração dos Direitos do Retardo Mental, que afirma que as pessoas com deficiência mental têm os mesmos direitos dos demais seres humanos. Em 1975, a Assembleia Geral da ONU aprova a resolução $n^{\circ}$. 34/47 relacionada à Declaração dos Direitos das Pessoas com Deficiência, ${ }^{5}$ afirmando que estas têm o direito inerente ao respeito à sua dignidade, aos mesmos direitos civis, políticos, econômicos, sociais e culturais que as demais pessoas, aliados ao "direito de terem tratamentos médicos, psicológico e funcional, à reabilitação, aos serviços de colocação e a outros serviços que lhes possibilitarão desenvolver suas capacidades e habilidades ao máximo e acelerarão o processo de sua integração ou reintegração social, "o que implica, antes de tudo, no direito de desfrutar de uma vida decente, normal e plena".

No ano de 1981, foi proclamado pela Assembleia Geral das Nações Unidas, pela Resolução n. 31/123, o Ano Internacional das Pessoas com Deficiência, com o tema "Participação e Igualdade", com ênfase na prevenção, reabilitação e equiparação de oportunidades. O propósito dessa declaração universalmente conhecida era dar condições para a implementação das Resoluções anteriores, por meio da conscientização do mundo todo quanto à problemática das pessoas com deficiências (SILVA, 2009).

A Declaração definiu o termo "pessoas deficientes" como qualquer pessoa incapaz de assegurar por si mesma, total ou parcialmente, as necessidades de uma vida individual ou social normal, em decorrência de uma deficiência, congênita ou não, em suas capacidades físicas ou mentais. 
Nesse contexto, surge o processo de integração social com o intuito de derrubar a prática da exclusão a que foram submetidas as pessoas com deficiência por vários séculos, começando sua inserção nos sistemas sociais gerais, como a educação, o trabalho, a família e o lazer.

Essa nova orientação, pouco exigia da sociedade em termos de modificação de atitudes, de objetos, de práticas sociais e de espaços físicos. Afinal, a pessoa com deficiência é que teria que se transformar, se modificar e se adequar às exigências da sociedade. Esperava-se que, após a reabilitação, a pessoa com deficiência reabilitada estivesse apta a assumir o seu lugar na sociedade.

Era um processo de mão única, em que a sociedade ficava de braços cruzados, aceitava receber as pessoas com deficiência, mas essas tinham que se amoldar aos serviços especiais, ficando separadas em classe especial, acompanhando os procedimentos tradicionais, contornando os obstáculos existentes no meio físico, lidando com a discriminação da sociedade e desempenhando com autonomia, mas não necessariamente independência os papéis de aluno, trabalhador, pai, consumidor etc. (SASSAKI, 1999, p. 35).

Esse modelo mostrou que tal prática social era insuficiente para acabar com a discriminação, como também pouco eficiente para propiciar a verdadeira participação das pessoas com deficiência em igualdade de oportunidades no âmbito social.

A Assembleia Geral da ONU, nos anos subsequentes, caminhou gradativamente para uma desejável conscientização quanto à garantia não apenas dos direitos, mas, também, dos meios para que as pessoas com deficiência tivessem condições de acesso à sociedade de forma plena e em igualdade de condições.

No ano de 1993, a Assembleia Geral da ONU adotou o documento "Normas sobre a Equiparação de Oportunidades para as Pessoas com deficiência" (Resolução 44/70). Em todas as definições trazidas por essa norma está implícito o princípio da igualdade de direitos. No seu parágrafo 24, definiu o termo equiparação de oportunidades como o processo por intermédio do 
qual os diversos sistemas da sociedade e do ambiente, como serviços, atividades, informações e documentação, são tornados disponíveis para todos, particularmente para pessoas com deficiência. Essas recomendações se destacaram das demais resoluções da ONU na área da deficiência e tiveram uma importância significativa na história normativa de seus direitos, tanto que serviram de parâmetro para práticas de políticas e leis de muitos países. No Brasil, o Decreto ${ }^{\circ}$. 3.298/99, que regulamentou a Lei $n^{\circ}$. 7.853/89, definiu a Política de Integração Nacional da Pessoa Portadora de Deficiência com base nessas normas adotadas pela ONU.

$\mathrm{Na}$ tentativa de avançar no processo de construção de uma sociedade que respeite a diversidade, teve início o movimento de inclusão social, cujo objetivo é a construção de uma sociedade para todas as pessoas: não cabe somente às pessoas com deficiência se integrarem à sociedade. É preciso que a sociedade também se transforme, para acolher todos os seus cidadãos.

Conforme ensina Sassaki (1999, p. 17), a inclusão se inspira em novos princípios, quais sejam: celebração de diferenças, direito de pertencer, valorização da diversidade humana, solidariedade humanitária, igual importância das minorias e cidadania com qualidade de vida.

A inclusão social pode ser conceituada como um processo pelo qual a sociedade se adapta para poder incluir as pessoas com deficiência e, simultaneamente, estas se preparam para assumir seus papéis na sociedade (SASSAKI, 1999, p. 41). Por conseguinte, a inclusão social é um processo de mão dupla, ou seja, tanto a pessoa com deficiência como a sociedade precisam se modificar.

É um processo que demandará a construção de um novo tipo de sociedade por meio de transformações, pequenas e grandes, na mentalidade de todas as pessoas e, especificamente, após o advento da Convenção dos Direitos da Pessoa com Deficiência, no que refere à realização dos direitos fundamentais, especialmente a educação inclusiva, conforme adiante será abordado. 


\section{Direito fundamental à educação inclusiva}

Direitos fundamentais são normas que estabelecem direitos e limitações aos particulares e ao Estado, visando possibilitar o convívio social e concretizar a dignidade da pessoa humana.

A educação é primordial para o desenvolvimento humano e para uma cultura da paz e do respeito ao outro. É, certamente, uma das aspirações de natureza social mais significativas para transformar e melhorar a vida das pessoas.

A educação pode ser avaliada como uma necessidade básica para que se construa um mundo mais justo e igualitário, promovendo, em cada indivíduo, a compreensão de sua situação no tempo e no espaço e, por conseguinte, a possibilidade de melhoria (intelectual e social).

Tem assento logo a partir do título II da Constituição Federal de 1988 (que trata dos "Direitos e Garantias Fundamentais"), no capítulo II (destinado especificamente aos "Direitos Sociais"), cujo artigo $6^{\circ}$., mesmo na redação original da Carta da República, já o consagrava como um direito social. Ainda com o advento das Emendas Constitucionais nº. 26, de 2000, nº. 64, de 2010, e nº. 90, de 2015, essa classificação não se alterou, pois a atual redação do artigo proclama abertamente, in verbis:

\section{(...)}

Artigo $6^{\circ}$. São direitos sociais a educação, a saúde, a alimentação, o trabalho, a moradia, o transporte, o lazer, a segurança, a previdência social, a proteção à maternidade e à infância, a assistência aos desamparados, na forma desta Constituição (...)

Mais adiante, na Lei Fundamental de 1988, a partir do título VIII (que versa sobre a "Ordem Social"), no bojo do Capítulo III (cujo objeto cuida "Da Educação, da Cultura e do Desporto"), chegamos à Seção I, onde estão inseridos os artigos 205 a 214 (que tratam especificamente "Da Educação") que constituem a base da organização educacional do país, estabelecendo os princípios, os direitos e os deveres, as competências, a vinculação de recursos e a prioridade para a sua distribuição. 
Foi no artigo 205 que o Texto Fundamental da República especificou o referido direito:

(...)

Artigo 205. A educação, direito de todos e dever do Estado e da família, será promovida e incentivada com a colaboração da sociedade, visando ao pleno desenvolvimento da pessoa, seu preparo para o exercício da cidadania e sua qualificação para o trabalho (...)

Da leitura do dispositivo, conclui-se que o direito à educação deve visar ao pleno desenvolvimento da pessoa, seu preparo para o exercício da cidadania e a sua qualificação para o trabalho. Esses objetivos expressam o sentido que a Constituição concedeu ao direito fundamental à educação.

Tem-se, a partir daqui, de compreender um conteúdo da própria educação, como direito fundamental. Não se trata mais de qualquer direito à educação, mas daquele cujas balizas foram construídas constitucionalmente.

Isso significa que o direito à educação é o direito de acesso, mas não um acesso a qualquer educação, e sim àquela que atende às preocupações constitucionais, entre as quais a da educação inclusiva.

Entende-se por educação inclusiva um novo modelo de ensino dos dias atuais no qual o objetivo principal é a garantia de que todos, absolutamente todos, tenham acesso à educação. Estender para todos o direito à educação é, antes de tudo, respeitar o dogma da igualdade, especialmente no que concerne às oportunidades que cada indivíduo deve receber para ter acesso ao direito à educação, valorizando assim as diferenças humanas e, por conseguinte, contemplando as diversidades étnicas, sociais, culturais, intelectuais, físicas, sensoriais e de gênero das pessoas.

Nesse sentido, aponta Maria Tereza Eglér Mantoan que “as diferenças culturais, sociais, étnicas, religiosas, de gênero, enfim, a diversidade humana está sendo cada vez mais desvelada e destacada e é condição imprescindível para se entender como aprendemos e como compreendemos o mundo e a nós mesmos" (MANTOAN, 2003, p. 12). 
Naturalmente, esse novo modelo, essa verdadeira reviravolta institucional, demanda uma profunda reestruturação não só da cultura, mas também das práticas e políticas vigentes na escola e, mais além, no próprio sistema de ensino. Afinal, há de se garantir em primeiro lugar, o acesso; depois a participação; por fim, a aprendizagem à todos sem exceção, algo que vai ao encontro do que preconiza o princípio fundamental da República Federativa do Brasil da dignidade da pessoa humana.

Em todo o mundo, a educação inclusiva vem permitindo que estudantes com e sem deficiência percorram sua trajetória escolar lado a lado, na mesma sala de aula. A educação inclusiva é a prática indicada e reafirmada em diversas declarações internacionais, leis nacionais e políticas de educação.

Essas políticas, somadas aos esforços dos defensores dos direitos das pessoas com deficiência, têm levado a um aumento substancial do número de alunos com deficiência que recebem educação escolar junto de seus colegas sem deficiência (HEHIR, 2016, p. 2).

A inclusão de pessoas com deficiência nas escolas comuns na rede regular de ensino coloca novos e grandes desafios para o sistema educacional. Em nosso país, escola inclusiva é uma escola comum, que recebe a todos, independentemente das diferenças. Ocorre que a maioria das escolas regulares do Brasil não está preparada para recepcionar e ensinar os alunos com deficiência, especialmente por falta de estrutura e formação profissional da equipe.

A realidade brasileira é que o aluno com deficiência está matriculado numa escola regular, mas dependendo da sua necessidade, pode precisar frequentar também uma escola especial para ter atendimento educacional especializado.

Na educação inclusiva, todos os alunos com e sem deficiência têm a oportunidade de conviver e aprender juntos. É o que Mantoan chamou de cidadania global, plena, livre de preconceitos e que reconhece e valoriza as diferenças (MANTOAN, 2003, p. 14).

$\mathrm{O}$ direito à educação inclusiva pressupõe uma escola na qual os professores trabalham em conjunto para elevar o desempenho 
dos alunos por meio de uma constante melhora no seu ensino, apoiando as necessidades individuais de aprendizagem de cada um deles; esses professores valorizam a diversidade em tudo, não apenas a diversidade cultural ou racial, mas a diversidade na forma como se aprende e também a diversidade de fatores econômicos.

Essas escolas funcionam como organizações colaborativas de solução de problemas. Em vez de operar de forma isolada, professores e funcionários trabalham juntos para personalizar programas para cada estudante. Essa solução coletiva de problemas promove uma cultura de inovação e melhoria em que os professores se esforçam continuamente para atender às constantes mudanças das necessidades de todos os alunos (HEHIR, 2016, p. 11).

Existem inúmeros desafios que são associados ao ensino dos alunos com deficiência. Mas, tais desafios se tornam, na realidade, fonte de oportunidade para reforçar a prática profissional desses docentes e a possibilidade de melhorar o desempenho de todos os alunos, tenham eles deficiência ou não.

A convivência entre crianças com e sem deficiência é benéfica para ambas. Ganham os alunos com deficiência, à medida que convivem em um ambiente desafiador, provocador, rico em experiências, que os incentive a pensar. E ganham os alunos sem deficiência por terem oportunidade de aprender com as diferenças do outro, vivenciarem novas formas de construir conhecimento e de se comunicar (libras, braile, recursos da tecnologia assistiva e da comunicação alternativa e aumentativa, entre outros) e, acima de tudo, por terem a oportunidade de vivenciar verdadeiros momentos de colaboração, ajuda mútua e solidariedade, tão necessários em nossos dias. E essa afirmativa é tão verdadeira que muitos são os pais de crianças sem deficiência que lutam pelo direito de seus filhos terem colegas com deficiências.

A educação inclusiva gera efeitos benéficos a todos os estudantes, não apenas àqueles que têm alguma deficiência. Além de promover ganhos na socialização e no desenvolvimento emocional de todos, ela favorece o desenvolvimento cognitivo de 
crianças e jovens com deficiência. Em certos contextos, o convívio favorece também o desenvolvimento intelectual e socioemocional dos alunos sem deficiência.

Essas são algumas das principais conclusões do estudo Os beneficios da educação inclusiva para estudantes com e sem deficiência, coordenado pelo professor Thomas Hehir, da Escola de Educação de Harvard, lançado, em 2016, pelo Instituto Alana e ABT Associates. A análise compila resultados de mais de 89 estudos, selecionados num universo de 280 artigos publicados em 25 países, realizados por meio de diversas metodologias e com diferentes populações de estudantes.

Existem evidências claras e consistentes apontando que ambientes educacionais inclusivos podem oferecer benefícios significativos de curto e longo prazos aos alunos com e sem deficiência. Um grande número de pesquisas indica que estudantes incluídos desenvolvem habilidades mais fortes em leitura e matemática, têm maiores taxas de presença, são menos propensos a ter problemas comportamentais e estão mais aptos a completar o ensino médio, comparado com estudantes que não são incluídos. Quando adultos, alunos com deficiência que foram incluídos são mais propensos a ser matriculados no ensino superior, encontrar um emprego ou viver de forma independente (HEHIR, 2016, p. 2).

Nesse sentido, afirma Mantoan que "o movimento inclusivo, nas escolas, por mais que ainda seja muito contestado, pelo caráter ameaçador de toda e qualquer mudança, especialmente no meio educacional, convence a todos pela sua lógica e pela ética de seu posicionamento social" (MANTOAN, 2003, p. 48).

Com os olhos voltados para esses valores, conceitos e definições, passaremos a identificar agora os principais diplomas legislativos no ordenamento jurídico brasileiro que veiculam o tema.

\section{Avanços legislativos do direito à educação inclusiva no ordenamento jurídico brasileiro}

No Brasil, especificamente no que se refere à educação inclusiva, o tratamento legal dado à questão é bastante recente. A 
primeira lei que fixa Diretrizes e Bases da Educação Nacional foi a lei $\mathrm{n}^{\circ}$. 4.024, de 20 de dezembro de 1961, cujo título X estabelecia os parâmetros "Da Educação dos Excepcionais".

Apesar da impropriedade terminológica do título mencionado, tal diploma já preceituava a necessidade da integração de todos no sistema geral de educação e também a destinação de bolsas de estudo, empréstimos e subvenções para as iniciativas consideradas eficientes destinadas à educação dos excepcionais.

Em 1988, foi promulgada a Constituição da República Federativa do Brasil, que não só abordou de maneira aprofundada o direito à educação como também deu especial ênfase às pessoas com deficiência. No ano seguinte, e com o intuito de regulamentar os mandamentos constitucionais da Carta recém promulgada, foi publicada a lei 7.853, de 24 de outubro de 1989, que dispõe sobre o apoio às pessoas portadoras de deficiência, sua integração social, sobre a Coordenadoria Nacional para Integração da Pessoa Portadora de Deficiência - Corde, institui a tutela jurisdicional de interesses coletivos ou difusos dessas pessoas, disciplina a atuação do Ministério Público, define crimes, e dá outras providências. Em seu artigo $2^{\circ}$., essa lei preceitua que “...Ao Poder Público e seus órgãos cabe assegurar às pessoas portadoras de deficiência o pleno exercício de seus direitos básicos, inclusive dos direitos à educação, à saúde, ao trabalho, ao lazer, à previdência social, ao amparo à infância e à maternidade, e de outros que, decorrentes da Constituição e das leis, propiciem seu bem-estar pessoal, social e econômico".

Coube ao Decreto $\mathrm{n}^{\circ}$. 3.298/99, publicado em 20 de dezembro de 1999, a tarefa de regulamentar essa lei, pois regulamenta a Lei $n^{\circ} .7 .853$, de 24 de outubro de 1989, dispõe sobre a Política Nacional para a Integração da Pessoa Portadora de Deficiência, consolida as normas de proteção, e dá outras providências. Além de dispor sobre a Política Nacional para a Integração da Pessoa com deficiência, esse diploma teve o grande mérito de definir quem são as pessoas com deficiência pelo estabelecimento de uma série de categorias, nos seus artigos $3^{\circ}$. e $4^{\circ}$. Mais tarde, em 20 de dezembro de 2004, o Decreto $n^{\circ}$. $5.296 / 04$ deu nova redação ao artigo $4^{\circ}$. e revogou outros tantos do decreto regulamentador inicial de 1999. 
Em 13 de julho de 1990, foi publicada a lei 8.069/90, que Dispõe sobre o Estatuto da Criança e do Adolescente e dá outras providências, cujo capítulo IV trata do Direito à educação, à Cultura, ao Esporte e ao Lazer, e traz em seu artigo 54 a determinação de que "É dever do Estado assegurar à criança e ao adolescente: inciso III: atendimento educacional especializado aos portadores de deficiência, preferencialmente na rede regular de ensino".

No ano de 1996, foi publicada uma nova Lei de Diretrizes e Bases da Educação, já elaborada sob os auspícios da Constituição de 1988 e, portanto, regulamentadora dos direitos constitucionalmente previstos.

Trata-se da lei 9.394/96, de 20 de dezembro de 1996, que estabelece as diretrizes e bases da educação nacional. De especial relevância para os fins deste trabalho é o Capítulo $\mathrm{V}$ desse diploma, que trata Da Educação Especial.

Inserido nesse capítulo, o artigo 58, na sua redação original, preceituava que "entende-se por educação especial, para os efeitos desta Lei, a modalidade de educação escolar, oferecida preferencialmente na rede regular de ensino, para educandos portadores de necessidades especiais".

Mais tarde, a redação desse artigo foi atualizada pela lei 12.796/2013, e passou a figurar da seguinte maneira: "Entendese por educação especial, para os efeitos desta Lei, a modalidade de educação escolar oferecida preferencialmente na rede regular de ensino, para educandos com deficiência, transtornos globais do desenvolvimento e altas habilidades ou superdotação".

No ano de 2000, mais especificamente no dia 19 de dezembro, foi publicada a lei no ${ }^{\circ}$ 10.098/2000, que estabelece normas gerais e critérios básicos para a promoção da acessibilidade das pessoas portadoras de deficiência ou com mobilidade reduzida, e dá outras providências.

O artigo 17, dessa lei, trata da educação inclusiva ao determinar que “o Poder Público promoverá a eliminação de barreiras na comunicação e estabelecerá mecanismos e alternativas técnicas que tornem acessíveis os sistemas de comunicação e sinalização às pessoas portadoras de deficiência sensorial e com 
dificuldade de comunicação, para garantir-lhes o direito de acesso à informação, à comunicação, ao trabalho, à educação, ao transporte, à cultura, ao esporte e ao lazer".

Conforme já mencionado, o Capítulo V da Lei de Diretrizes e Bases de 1996 (lei 9.396/96) tratou especificamente Da Educação Especial. Em atendimento ao disposto nesse capítulo, no dia 11 de setembro de 2001 o Conselho Nacional Educação fez publicar a Resolução CNE/CEB No. 2, que institui Diretrizes Nacionais para a Educação Especial na Educação Básica, sendo esse o documento fundamental das proposições nacionais voltadas para a educação inclusiva.

Por se tratar de um marco na efetiva concepção de educação inclusiva no Brasil, destacamos a especial relevância dos artigos $2^{\circ}$. e $7^{\circ}$. desse diploma, que estabelecem:

(...)

Artigo $2^{\circ}$. Os sistemas de ensino devem matricular todos os alunos, cabendo às escolas organizar-se para o atendimento aos educandos com necessidades educacionais especiais, assegurando as condições necessárias para uma educação de qualidade para todos.

Parágrafo único. Os sistemas de ensino devem conhecer a demanda real de atendimento a alunos com necessidades educacionais especiais, mediante a criação de sistemas de informação e o estabelecimento de interface com os órgãos governamentais responsáveis pelo Censo Escolar e pelo Censo Demográfico, para atender a todas as variáveis implícitas à qualidade do processo formativo desses alunos

(...)

Artigo $7^{\circ}$. O atendimento aos alunos com necessidades educacionais especiais deve ser realizado em classes comuns do ensino regular, em qualquer etapa ou modalidade da Educação Básica (...)

Nessa altura dos acontecimentos, já se podia notar o amadurecimento que a legislação destinada à educação inclusiva apresentava no nosso ordenamento jurídico. Entrementes, uma situação extremamente relevante se desenrolava no cenário internacional, no âmbito da Organização das Nações Unidas (ONU). 
Alguns dos mais relevantes princípios instituídos pela Declaração Universal dos Direitos Humanos foram os direitos à vida, à igualdade, à não discriminação, à liberdade de locomoção e o direito ao trabalho. Tendo como base os princípios da Declaração Universal, a ONU, em 30 de março de 2007, editou a Convenção Internacional sobre os Direitos das Pessoas com Deficiência.

A Convenção Internacional sobre os Direitos das Pessoas com Deficiência é um instrumento internacional de direitos humanos das Nações Unidas, cuja finalidade é proteger os direitos e a dignidade das pessoas com deficiência.

Essa Convenção, assinada em Nova Iorque, aprovada pelo Congresso Nacional, por meio do Decreto Legislativo $n^{\circ} .186$, de 9 de julho de 2008, e promulgada pela Presidência da República, em 25 de agosto de 2009, pelo Decreto no . 6.949, de 25 de agosto de 2009, passou a ter o status de Emenda Constitucional por força do $\$ 3^{\circ}$., Artigo 5․, da Carta de 1988.

\footnotetext{
Por conta desse status constitucional de que passou a gozar a Convenção, fica assegurado o sistema educacional inclusivo em todos os níveis, assim garantindo que as pessoas com deficiência, de qualquer idade não sejam excluídas do sistema educacional geral, em nenhum nível, sob alegação de deficiência, assim como que recebam o apoio necessário, no âmbito desse mesmo sistema educacional geral, com vistas a facilitar sua efetiva educação... (BRAGA; FEITOSA, 2016, p. 348).
}

Em 17 de novembro de 2011, foi publicado o Decreto $n^{\circ}$. 7.611/2011, que dispõe sobre a educasão especial, o atendimento educacional especializado e dá outras providências. A finalidade desse decreto foi a de adequar a legislação infraconstitucional aos termos da Convenção que fora recentemente internalizada em nosso arcabouço legal. Por conta dessa adequação, fica estabelecido no ordenamento jurídico brasileiro o alcance da concepção da educação inclusiva, já que estabelece o atendimento às necessidades específicas das pessoas com deficiência, priorizando sua inserção no ensino regular e garantindo sua participação e desenvolvimento escolar pleno. 
No dia 27 de dezembro de 2012, foi publicada a lei 12.764/2012, que Institui a Política Nacional de Proteção dos Direitos da Pessoa com Transtorno do Espectro Autista; e altera o $\int 3^{\circ}$., do art. 98, da Lei $n^{\circ}$. 8.112, de 11 de dezembro de 1990.

Por fim, foi publicado o diploma que passou a ser conhecido como Estatuto da Pessoa com Deficiência, a Lei Brasileira de Inclusão, marco legal essencial para a concretização de seus direitos fundamentais. Trata-se da lei 13.146/2015, de 6 de julho de 2015, cujo destaque, para os fins deste trabalho, é o artigo 27 e seu parágrafo, que reproduzimos:

(...)

Artigo 27. A educação constitui direito da pessoa com deficiência, assegurados sistema educacional inclusivo em todos os níveis $\mathrm{e}$ aprendizado ao longo de toda a vida, de forma a alcançar o máximo desenvolvimento possível de seus talentos e habilidades físicas, sensoriais, intelectuais e sociais, segundo suas características, interesses e necessidades de aprendizagem.

Parágrafo único. É dever do Estado, da família, da comunidade escolar e da sociedade assegurar educação de qualidade à pessoa com deficiência, colocando-a a salvo de toda forma de violência, negligência e discriminação (...)

Com efeito, esses são os principais diplomas legislativos do Brasil voltados ao direito fundamental da educação inclusiva.

Nesse sentido, especial relevância deve ser dada à internalização da Convenção Internacional sobre os direitos da Pessoa com Deficiência em nosso ordenamento jurídico, com equivalência de norma constitucional e a publicação da lei regulamentadora desses direitos, o Estatuto da Pessoa com Deficiência, também chamada de Lei Brasileira de Inclusão.

\section{Considerações finais}

Por muito tempo, a pessoa com deficiência foi solenemente ignorada pela nossa sociedade. Somente com o advento das grandes 
guerras do século XX é que se passa a notar uma sensibilização e conscientização positivas sobre esses indivíduos.

O direito fundamental à educação é direito social com assento constitucional que pressupõe não apenas o acesso à educação, mas, além disso, a oferta de educação digna, qualificada e voltada para todas as pessoas indistintamente. Corolário indissociável disso é a imperiosidade de se evoluir da situação de exclusão e segregação que vigia para a desejável integração e inclusão de todas as pessoas com deficiência.

A transformação da mentalidade do sistema de ensino para um modelo inclusivista requer de todos os atores envolvidos uma verdadeira reviravolta institucional, que irá demandar uma profunda reestruturação não só da cultura, mas também das práticas e políticas vigentes na escola e, mais além, no próprio sistema de ensino, afinal, há de se garantir, em primeiro lugar, o acesso; depois a participação; por fim, a aprendizagem a todos sem exceção, algo que vai ao encontro do que preconiza o princípio fundamental da República Federativa do Brasil da dignidade da pessoa humana.

Para se alcançar esses anseios, o Brasil dispõe de uma legislação moderna e apta a disponibilizar a todas as pessoas com deficiência educação inclusiva de qualidade. Extremamente relevante nesse cenário é a Lei Brasileira de Inclusão, o verdadeiro Estatuto da Pessoa com Deficiência. Obviamente, apesar dos aspectos inovadores dessa lei, ela não pode ser entendida como uma linha de chegada, uma tarefa já executada, mas sim como um ponto de partida que, acompanhando a natureza dinâmica da vida em sociedade, possa ser o passo inicial para a desejável evolução.

\section{Referências}

ARAÚJO, Luiz Alberto David. A proteção constitucional das pessoas portadoras de deficiência, 2. ed. Brasília: CORDE, 1997.

BRAGA, Janice de Carvalho Ferreira; FEITOSA, Gustavo Raposo Pereira.

Direito à Educação da Pessoa com Deficiência Transformações Normativas e a Expansão da Inclusão no Brasil. Revista Direitos Humanos e Democracia. Editora Unijuí, ano 4, n. 8, jul./dez. 2016. Disponível 
em: file:///C:/Users/flavia\%20piva/Downloads/6335-Texto $\% 20$ do $\% 20$ artigo-28708-1-10-20161216\%20(1).pdf Acesso 6. nov. 2018.

BRASIL. Constituição da República Federativa do Brasil. Disponível em: <http://www.planalto.gov.br/ccivil_03/constituicao/constituicaocompilado. htm> Acesso em: 8. nov. 2018.

BRASIL. Decreto 3298/99. Regulamenta a Lei nº 7.853 , de 24 de outubro de 1989, dispõe sobre a Política Nacional para a Integração da Pessoa Portadora de Deficiência, consolida as normas de proteção, e dá outras providências. Disponível em: <http://www.planalto.gov.br/ccivil_03/decreto/d3298.htm> Acesso em: 8. nov. 2018.

BRASIL. Decreto 6.949/09. Promulga a Convenção Internacional sobre os Direitos das Pessoas com Deficiência e seu Protocolo Facultativo, assinados em Nova York, em 30 de março de 2007. Disponível em: <http:/ /www.planalto.gov. br/ccivil_03/_Ato2007-2010/2009/Decreto/D6949.htm> Acesso em 8. nov. 2018.

BRASIL. Decreto 7.611/11. Dispõe sobre a educação especial, o atendimento educacional especializado e dá outras providências. Disponível em: <http:// www.planalto.gov.br/ccivil_03/_ato2011-2014/2011/decreto/d7611.htm> Acesso em 8. nov. 2018.

BRASIL. Lei 4.024/61. Fixa diretrizes e bases da Educação Nacional. Disponível em: <http://www.planalto.gov.br/ccivil_03/LEIS/L4024.htm> Acesso em: 8. nov. 2018.

BRASIL. Lei 7.853/89. Dispõe sobre o apoio às pessoas portadoras de deficiência, sua integração social, sobre a Coordenadoria Nacional para Integração da Pessoa Portadora de Deficiência - Corde, institui a tutela jurisdicional de interesses coletivos ou difusos dessas pessoas, disciplina a atuação do Ministério Público, define crimes, e dá outras providências. Disponível em: <http://www.planalto. gov.br/ccivil_03/leis/L7853.htm> Acesso em: 8. nov. 2018.

BRASIL. Lei 8.069/90. Dispõe sobre o Estatuto da Criança e do Adolescente e dá outras providências. Disponível em: < http://www.planalto.gov.br/ccivil_03/ LEIS/L8069.htm> Acesso em: 8. nov. 2018.

BRASIL. Lei 9.394/96. Estabelece diretrizes e bases da educação nacional. Disponível em: <http://www.planalto.gov.br/ccivil_03/Leis/L9394.htm> Acesso em 8. nov. 2018.

BRASIL. Lei 10.098/00. Estabelece normas gerais e critérios básicos para a promoção da acessibilidade das pessoas portadoras de deficiência ou com mobilidade reduzida, e dá outras providências. Disponível em: <http://www. planalto.gov.br/ccivil_03/LEIS/L10098.htm> Acesso em: 8. nov. 2018. 
BRASIL. Lei 12.764/12. Institui a Política Nacional de Proteção dos Direitos da Pessoa com Transtorno do Espectro Autista; e altera o $\int 3^{\circ}$. do art. 98 da Lei $n^{\circ}$. 8.112, de 11 de dezembro de 1990. Disponível em: <http://www.planalto.gov.br/ ccivil_03/_ato2011-2014/2012/lei/112764.htm> Acesso em: 8. nov. 2018.

BRASIL. Lei 13.146/2015. Institui a Lei Brasileira de Inclusão da Pessoa com Deficiência (Estatuto da Pessoa com Deficiência). Disponível em: $\leq$ http://www. planalto.gov.br/ccivil_03/_ato2015-2018/2015/lei/113146.htm $\geq$ Acesso em: 23. abr. 2018.

BRASIL. Resolução CNE/CEB 2/2001. Institui Diretrizes Nacionais para a Educação Especial na Educação Básica. Disponível em: <http://portal.mec.gov. br/cne/arquivos/pdf/CEB0201.pdf> Acesso em: 8. nov. 2018.

HEHIR, Thomas. (coordenação). Os benefícios da educação inclusiva para estudantes com e sem deficiência. Instituto Alana ABT Associates (2016). Disponível em: <https://alana.org.br/wpcontent/uploads/2016/11/Os_ Beneficios_da_Ed_Inclusiva_final.pdf.> Acesso em: 08/11/2018.

LOPES, Laís Vanessa Carvalho de Figueiredo. Convenção sobre os direitos das pessoas com deficiência da ONU. In: GUGEL, Maria Aparecida; COSTA FILHO, Waldir Macieira da; RIBEIRO, LAURO Luiz Gomes (Org.). Deficiência no Brasil - uma abordagem integrado dos direitos das pessoas com deficiência. Florianópolis: Obra Jurídica, 2007.

MANTOAN, Maria Tereza Eglér. Inclusão escolar: o que é? Por quê? Como fazer. Coleção cotidiana escolar. São Paulo: Moderna, 2003.

SARLET, Ingo Wofgangt; MARINONI, Luiz Guilherme; MITIDIERO, Daniel. Curso de Direito Constitucional, 3. edição revista, atualizada e ampliada. Thomson Reuters Revista dos Tribunais, São Paulo, 2014.

SASSAKI, Romeu Kazumi. Inclusão: construindo uma sociedade para todos, 3. ed. Rio de Janeiro: WVA, 1999.

SILVA, Otto Marques da. A epopeia ignorada. CD Epopeia ignorada. Cotia: Editora Faster, 2009.

TORRES, Marcelo Nóbrega da Câmara. Direitos Sociais. Brasília: Senado Federal, 1987.

Submetido em: 17-9-2018

Aceito em: 23-11-2018 